Check for updates

Cite this: RSC Adv., 2017, 7, 54898

Received 19th October 2017

Accepted 26th November 2017

DOI: 10.1039/c7ra11550d

rsc.li/rsc-advances

\section{Enhancing the performance of thin-film nanocomposite nanofiltration membranes using MAH-modified GO nanosheets}

\author{
Quanling Xie, (D) abe Wenyao Shao, ${ }^{\text {d }}$ Shishen Zhang, ${ }^{\text {bd }}$ Zhuan Hong, \\ Qiuquan Wang (D) *a and Birong Zeng (D)*c
}

In this work, novel thin-film nanocomposite (TFN) nanofiltration (NF) membranes were developed through modification with maleic anhydride functionalized graphene oxide (MAH-GO) via interfacial polymerization (IP). First, MAH-GO was synthesized by linking MAH molecules to the electrophilic groups (C-OH) of GO nanosheets. The resulting materials were characterized in depth by FT-IR, TEM, SEM, AFM, XPS and Raman spectroscopy. Subsequently, the MAH-GO and GO nanosheets were individually introduced into the polypiperazine-amide (PPA) active layer of TFN NF membranes via IP between piperazine (PIP) and trimesoyl chloride (TMC). The influence of the MAH-GO or GO concentrations on the morphology and performance of TFN NF membranes was systematically investigated. Compared with TFC-blank, the TFN-MG-60 and TFNGO-80 membranes demonstrated significantly enhanced separation performance without reduction of the salt rejection. Particularly, the water flux of TFN-MG-60 and TFN-GO-80 was found to be $49.3 \mathrm{~L} \mathrm{~m}^{-2} \mathrm{~h}^{-1}$ and $42.0 \mathrm{~L} \mathrm{~m}^{-2} \mathrm{~h}^{-1}$, respectively, corresponding to $176.7 \%$ and $150.5 \%$ of TFC-blank. Moreover, TFN-MG-60 demonstrated superior water permeability, antifouling capability and chlorine resistance to TFN-GO-80, which was attributed to the incorporation of $\mathrm{MAH}-\mathrm{GO}$ nanosheets having more hydrophilic carboxyl groups. Meanwhile, TFN-MG-60 retained a high salt rejection rate of $97.6 \%$ to $\mathrm{Na}_{2} \mathrm{SO}_{4}$, comparable to that of TFC-blank. The MAH-GO nanosheets show great potential in developing high-performance TFN NF membranes to overcome the trade-off effect of conventional thin-film composite membranes.

\section{Introduction}

Nanofiltration (NF) is the newest of the four classes of pressuredriven membranes whose molecular weight cut-off (MWCO) ranges from 150 to $1000 \mathrm{Da}$. It was originally developed to bridge the gap between reverse osmosis (RO) and ultrafiltration (UF). In contrast to asymmetric NF membranes prepared by the phase inversion method, NF membranes prepared by interfacial polymerization (IP) display superior properties such as higher permeability, rejection and selectivity. The development of thinfilm composite (TFC) membrane provides strong impetus to NF as a recognized and burgeoning alternative to conventional

${ }^{a}$ Department of Chemistry, The MOE Key Laboratory of Spectrochemical Analysis and Instrumentation, College of Chemistry and Chemical Engineering, Xiamen University, Xiamen 361005, China. E-mail: qqwang@xmu.edu.cn

${ }^{b}$ Engineering Research Center of Marine Biological Resource Comprehensive Utilization, SOA, The Third Institute of Oceanography of the State Oceanic Administration, Xiamen 361005, China

${ }^{c}$ Department of Materials Science and Engineering, College of Materials, Xiamen University, 361005, China.E-mail: brzeng@xmu.edu.cn

${ }^{d}$ Department of Chemical and Biochemical Engineering, College of Chemistry and Chemical Engineering, Xiamen University, Xiamen 361005, China

${ }^{e}$ Fujian Collaborative Innovation Center for Exploitation and Utilization of Marine Biological Resources, Xiamen, 361005, China separation techniques, as the top selective layer and bottom porous substrate of a TFC membrane can be independently controlled and optimized to achieve desired selectivity and permeability, while offering excellent mechanical strength and compression resistance. ${ }^{1}$ Currently, TFC NF are commonly applied in various industries such as water softening, food \& dairy, beverage, chemical engineering and pharmaceutical., ${ }^{\mathbf{1 , 2}}$ Despite that TFC NF membranes have been widely utilized in many industries, there are still substantial challenges for improving the permselectivity, ${ }^{3,4}$ anti-biofouling ${ }^{5}$ and chlorine resistance. ${ }^{6,7}$ In order to address these challenges, thin-film nanocomposite (TFN) membrane has been developed by incorporating an appropriate amount of nanomaterials in the bottom porous substrate ${ }^{\mathbf{8}, \mathbf{9}}$ as well as in the top selective layer to enhance the TFC NF performance. ${ }^{\mathbf{1 0} 11}$ The obtained TFN membranes have shown considerable potential to overcome the fluxrejection trade-off effect due to the unique features of. ${ }^{8}$ Many previous studies reported embedding various nanofillers (e.g. silicon dioxide, ${ }^{12-14} \mathrm{TiO}_{2}$ (ref. 15 and 16), MWCNT ${ }^{17-19}$ ) in polyamide (PA) selective layers to improve membrane performance.

In recent years, graphene oxide (GO) has recently attracted increasing research interest for its application in membrane materials, ${ }^{20-22}$ as it can act as a unique two-dimensional nanomaterial with abundant oxygen-containing functional groups 
(carboxyl, hydroxyl and epoxy) on their basal plane and edge. The presence of such hydrophilic groups grants GO outstanding dispersibility in polar organic solvent or aqueous medium, ${ }^{23}$ as well as provides the important reaction sites for further structural modification. In general, there are two different routes to incorporate GO into the PA selective layer: (I) GO is dispersed in aqueous phase containing aliphatic/aromatic diamine such as piperazine (PIP) and $m$-pheylenediamine (MPD); (II) GO is dispersed in organic phase containing acid chloride monomers such as trimesoyl chloride (TMC). The route (I) is often preferred because GO demonstrates better dispersibility in aqueous solution than in organic phase. ${ }^{9,24-26}$ Lai et al. ${ }^{8}$ and Wang et al..$^{27}$ investigated the effect of GO concentration in an aqueous PIP solution on membrane performance and found that TFN NF membrane with embedding an appropriate amount of GO exhibited better membrane performance owing to the remarkable increase in membrane hydrophilicity and surface negativity. Bano et $a .^{28}$ and Xia et $a l .{ }^{29}$ studied the effect of the GO concentration in an aqueous MPD solution on membrane performance and showed that GO-embedded TFN NF membranes offered higher water fluxes and better antifouling properties. In addition, GOembedded TFN membranes have also been developed as solvent-resistant NF to separate organic mixtures. ${ }^{30,31}$ In most of studies on GO-embedded TFN NF membranes, GO was directly utilized without structural modification.

GO has been demonstrated to be amphiphilic with an edgeto-center distribution of hydrophilic and hydrophobic domains. ${ }^{32-34}$ In order to further enhance its hydrophilicity, dispersibility and compatibility, GO was modified with maleic anhydride (MAH) to synthesize MAH functionalized GO (MAHGO) in this study. MAH-GO was incorporated in the polypiperazine-amide (PPA) active layer as a novel nanofiller during the interfacial polymerization (IP) process to improve the membrane performance. The effects of graphene-based nanosheets with different functional groups and concentrations on the surface morphology, hydrophilicity, separation performance, and antifouling properties of TFN NF membranes were systematically investigated in this study.

\section{Experimental}

\subsection{Materials}

Polysulfone (PSf) UF membrane supplied by Beijing Shengwanquan Membrane Technology Co. Ltd (China) was used as substrates of TFC membranes. The properties of PSf UF membrane are listed in Table 1.

PIP and TMC were provided by Shanghai Aladdin (China). Maleic anhydride (MAH), $n$-hexane, triethylamine (TEA), sodium hypochlorite $(\mathrm{NaOCl})$, hydrochloric acid $(\mathrm{HCl})$, sodium sulfate

Table 1 Properties of PSf UF membrane

\begin{tabular}{llll}
\hline $\begin{array}{l}\text { Membrane } \\
\text { material }\end{array}$ & $\begin{array}{l}\text { MWCO } \\
(\mathrm{Da})\end{array}$ & $\begin{array}{l}\text { Water flux } \\
\left(\mathrm{L} \mathrm{m}^{-2} \mathrm{~h}^{-1} \mathrm{bar}^{-1}\right)\end{array}$ & $\begin{array}{l}\text { Contact angle } \\
\left({ }^{\circ}\right)\end{array}$ \\
\hline PSf & 100000 & $224.6 \pm 10.8$ & $81.4 \pm 1.3$
\end{tabular}

$\left(\mathrm{Na}_{2} \mathrm{SO}_{4}\right)$, magnesium sulfate $\left(\mathrm{MgSO}_{4}\right)$, sodium chloride $(\mathrm{NaCl})$ and magnesium chloride $\left(\mathrm{MgCl}_{2}\right)$ were of analytical grade and obtained from Sinopharm Chemical Reagent Co. Ltd (China). Bovine serum albumin (BSA) was purchased from BBI life sciences (China). Water used in this study was purified by a Millipore system to achieve an electrical resistivity of $18.2 \mathrm{M} \Omega \mathrm{cm}$.

\subsection{Preparation of GO and MAH functionalized GO (MAH-GO)}

GO was prepared by a modified Hummers method as reported in our previous study. ${ }^{35}$ The process of MAH-GO fabrication was illustrated in Fig. 1. 0.25 GO powders were first added into $60 \mathrm{~mL}$ DMF solution and sonicated for $30 \mathrm{~min}$ to form a homogeneous solution. $0.98 \mathrm{~g}$ MAH was then added into the mixture solution with refluxing at $80{ }^{\circ} \mathrm{C}$ for $60 \mathrm{~min}$. Finally, the resulting product was washed with ethanol to remove the unreacted MAH and dried in vacuum to obtain the MAH-GO.

\subsection{Preparation of composite NF membrane}

Appropriate amounts of nanofillers (MAH-GO or GO) was added into the aqueous solution containing $2.0 \mathrm{wt} \%$ PIP and $2.0 \mathrm{wt} \%$ TEA, which was treated by the ultrasonic dispersion for $1 \mathrm{~h}$. The resulting aqueous solution was poured on the top of the PSf support membrane (fixed in a self-made polypropylene frame) and held for $2 \mathrm{~min}$. Then the excess aqueous solution was drained off and the residual droplets were removed from the membrane surface by nitrogen blowing. The PIP saturated support layer was then immersed in a solution of $0.1 \mathrm{w} / \mathrm{v} \% \mathrm{TMC}$ dissolved in $n$-hexane for $1 \mathrm{~min}$. After being cured at $60{ }^{\circ} \mathrm{C}$ for $8 \mathrm{~min}$, the prepared composite NF membranes were rinsed using pure water and immersed in pure water before use. The obtained composite membranes were named TFN-MG- $x$ or TFNGO- $x$, where $x$ denoted the aqueous solution containing $x$ ppm of MAH-GO or GO. The composite NF membrane without adding nanofiller was named TFC-blank.

\subsection{Characterization of GO and MAH-GO}

The chemical structures of GO and MAH-GO were characterized by Fourier transform infrared spectroscopy (FT-IR, Bruker VERTXE 70, Switzerland). Their morphologies were observed with a scanning electron microscope (SEM, Hitachi SU-70, Japan) operated at $10 \mathrm{kV}$, and a transmission electron microscopy (TEM, TALOS F200, USA) operated at $200 \mathrm{kV}$. Their surface characteristics were analyzed by an atomic force microscope (AFM, Bruker Nanoscope Multimode 8, Switzerland) in tapping-mode. Their surface groups were determined by an X-ray photoelectron spectroscopy (XPS, Thermo K-Alpha, USA). The $\mathrm{sp}^{2} / \mathrm{sp}^{3}$ carbon ratio was confirmed by Raman spectroscopy (Thermo Renishaw, USA). Their zeta-potentials were evaluated by particle-size analyzer (Nano-Zetasizer 90, Malvern Instruments, UK).

\subsection{Characterization of composite NF membranes}

The surface functional groups of the composite membranes were characterized by ATR-FTIR (Bruker VERTXE 70, Switzerland) and their surface compositions were characterized by XPS (Quantum 2000, Physical Instruments, USA). 


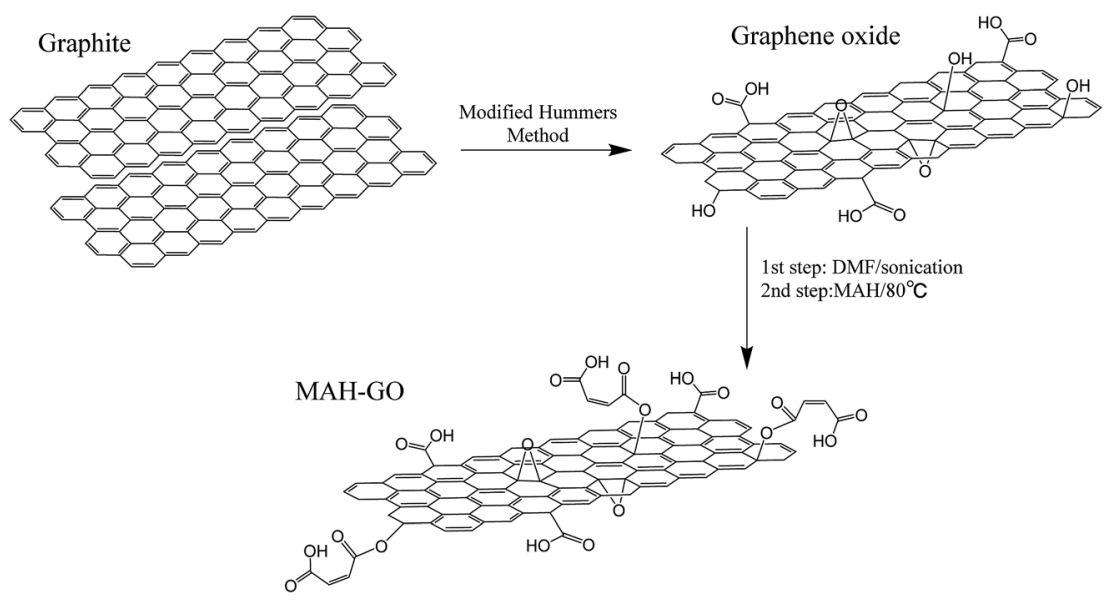

Fig. 1 Schematic of synthesis route of MAH-GO.

The surface hydrophilicities of composite membranes were evaluated using a contact angle goniometer (Beijing HARKE SPCAX3, China). At least five contact angles between water droplets and the top membrane surfaces were measured to minimize the experimental measurement error.

The cross-sectional morphologies of composite membranes were investigated with SEM (Zeiss Sigma, Germany) operated at $15 \mathrm{kV}$. The morphology and roughness were analyzed by AFM (MI5500, Agilent, USA) in tapping mode. The membrane surfaces were imaged at a scan size of $2 \mu \mathrm{m} \times 2 \mu \mathrm{m}$.

The membrane surface zeta potential was determined using SurPass Electrokinetic Analyser equipped with an adjustable cell (AntonPaar $\mathrm{GmbH}$, Austria) based on the streaming potential method. All analysis was carried out with $1 \mathrm{mM} \mathrm{KCl}$ back ground solution at $25{ }^{\circ} \mathrm{C}$ and the solution $\mathrm{pH}$ value was maintained between 3.0 and 10.0 by automatic addition of $0.1 \mathrm{M} \mathrm{HCl}$ or $0.1 \mathrm{M} \mathrm{KOH}$.

\subsection{Performance of composite NF membrane}

The membrane permselectivities were measured at $0.6 \mathrm{MPa}$ and $25{ }^{\circ} \mathrm{C}$ using a lab-scale cross-flow membrane separation device (FlowMem-0021-HP, FMT, China). The composite membranes were pre-pressurized under a pressure of $0.6 \mathrm{MPa}$ for $30 \mathrm{~min}$ to achieve a steady flux. Four different salt solutions $(2000 \mathrm{ppm}$ $\mathrm{Na}_{2} \mathrm{SO}_{4}, \mathrm{MgSO}_{4}, \mathrm{MgCl}_{2}$ or $\mathrm{NaCl}$ ) were used for rejection test. The key parameters of relevant ions are listed in Table $2 .{ }^{36}$ The water flux and the rejection $(R)$ were calculated using the eqn (1) and (2), respectively:

Table 2 Parameters of relevant ions ${ }^{a}$

\begin{tabular}{llll}
\hline & & $D$ & \\
Ions & $z$ & $\left(10^{-3} \mathrm{~mm}^{2} \mathrm{~s}^{-1}\right)$ & $r_{\mathrm{s}}(\mathrm{nm})$ \\
\hline $\mathrm{Na}^{+}$ & 1 & 1.333 & 0.183 \\
$\mathrm{Mg}^{+}$ & 2 & 0.706 & 0.345 \\
$\mathrm{Cl}^{-}$ & -1 & 2.032 & 0.120 \\
$\mathrm{SO}_{4}{ }^{2-}$ & -2 & 1.065 & 0.229
\end{tabular}

${ }^{a}$ Note: $z, D$ and $r_{\mathrm{s}}$ refer to the charge number, diffusion coefficient and Stokes radius.

$$
J=\frac{V}{A \Delta t}
$$

where $J$ is the water flux $\left(\mathrm{L} \mathrm{m}^{-2} \mathrm{~h}^{-1}\right), V$ is the volume of permeate (L), $A$ is the effective area of membrane $\left(\mathrm{m}^{2}\right)$, and $\Delta t$ is the filtration time $(\mathrm{h})$.

$$
R(\%)=\left(1-\frac{C_{\mathrm{p}}}{C_{\mathrm{f}}}\right) \times 100 \%
$$

where $C_{\mathrm{p}}$ and $C_{\mathrm{f}}$ refer to the solute concentration in the permeate and the feed solution, and were measured with a portable conductivity meter (METTLER TOLEDO SG3, Switzerland).

BSA was used as the model protein foulant in this study. The membrane fouling of the composite membranes were assessed according to the following procedure. First, the pure water flux was recorded for $60 \mathrm{~min}$ at a pressure of $0.6 \mathrm{MPa}$. Then 2000 ppm BSA solution was used to replace pure water and recycled continuously for another $60 \mathrm{~min}$. Subsequently, the fouled membranes were rinsed with the pure water, followed by filtration process with the pure water again. The fouling and water filtration procedures were repeated two times.

The chlorine resistance of the composite membranes were evaluated in terms of water flux and salt rejection before and after chlorine treatment. In order to eliminate the effect of acidic or basic condition, 2000 ppm sodium hypochlorite solution with neutral pH was used to examine the long-term chlorine stability. The NF membranes were immersed in the sodium hypochlorite solution for different interval period ( $24 \mathrm{~h}, 48 \mathrm{~h}$ and $72 \mathrm{~h}$ ). Before remeasuring membrane permselectivity, the chlorine-treated membranes were rinsed thoroughly and soaked in pure water for $1 \mathrm{~h}$. The performance of chlorine-treated membrane was tested under the same aforementioned conditions.

\section{Results and discussion}

\subsection{Characterization of GO and MAH-GO}

GO and MAH-GO present highly similar nanosheets structures with the wrinkled morphologies according to their TEM images (Fig. 2) and SEM images (Fig. 3). It is therefore shown that MAH 

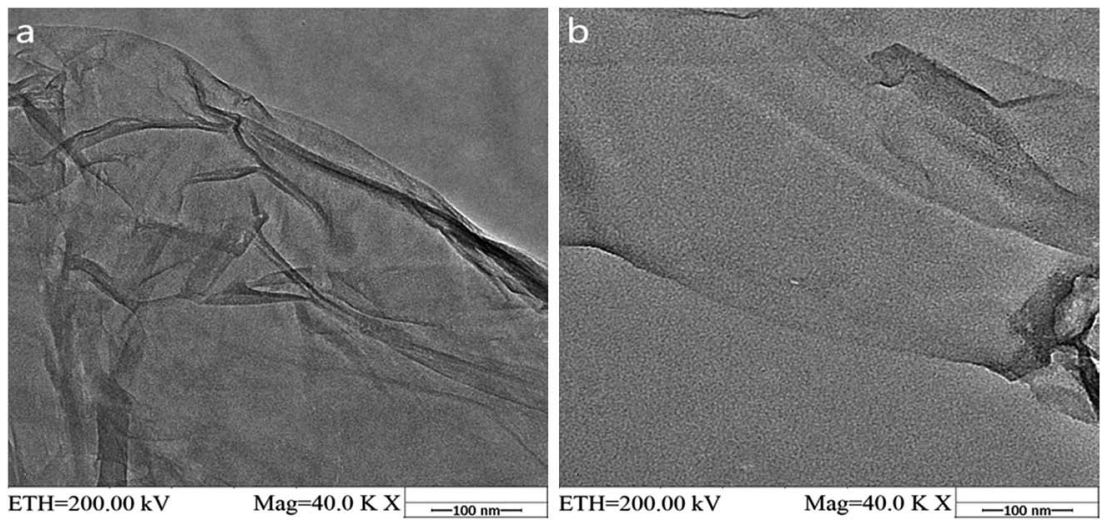

Fig. 2 TEM images of GO (a) and MAH-GO (b).
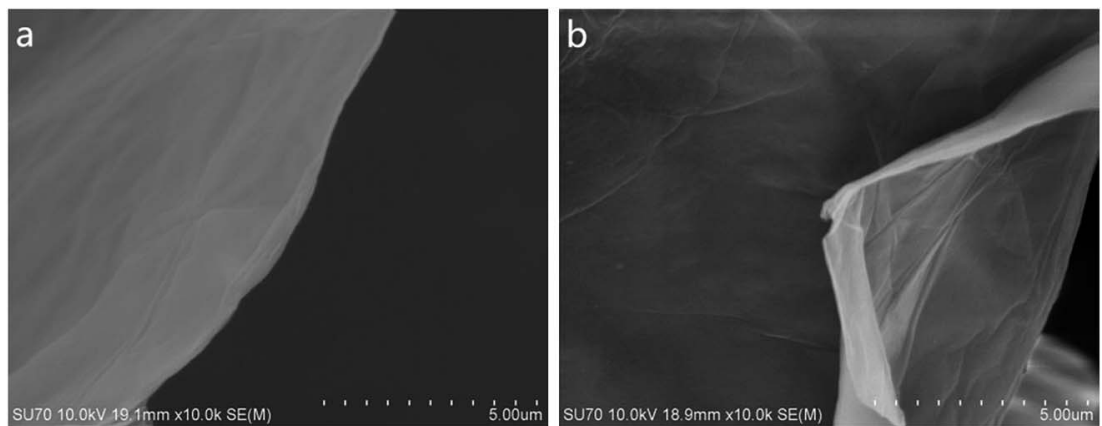

Fig. 3 SEM images of GO (a) and MAH-GO (b).
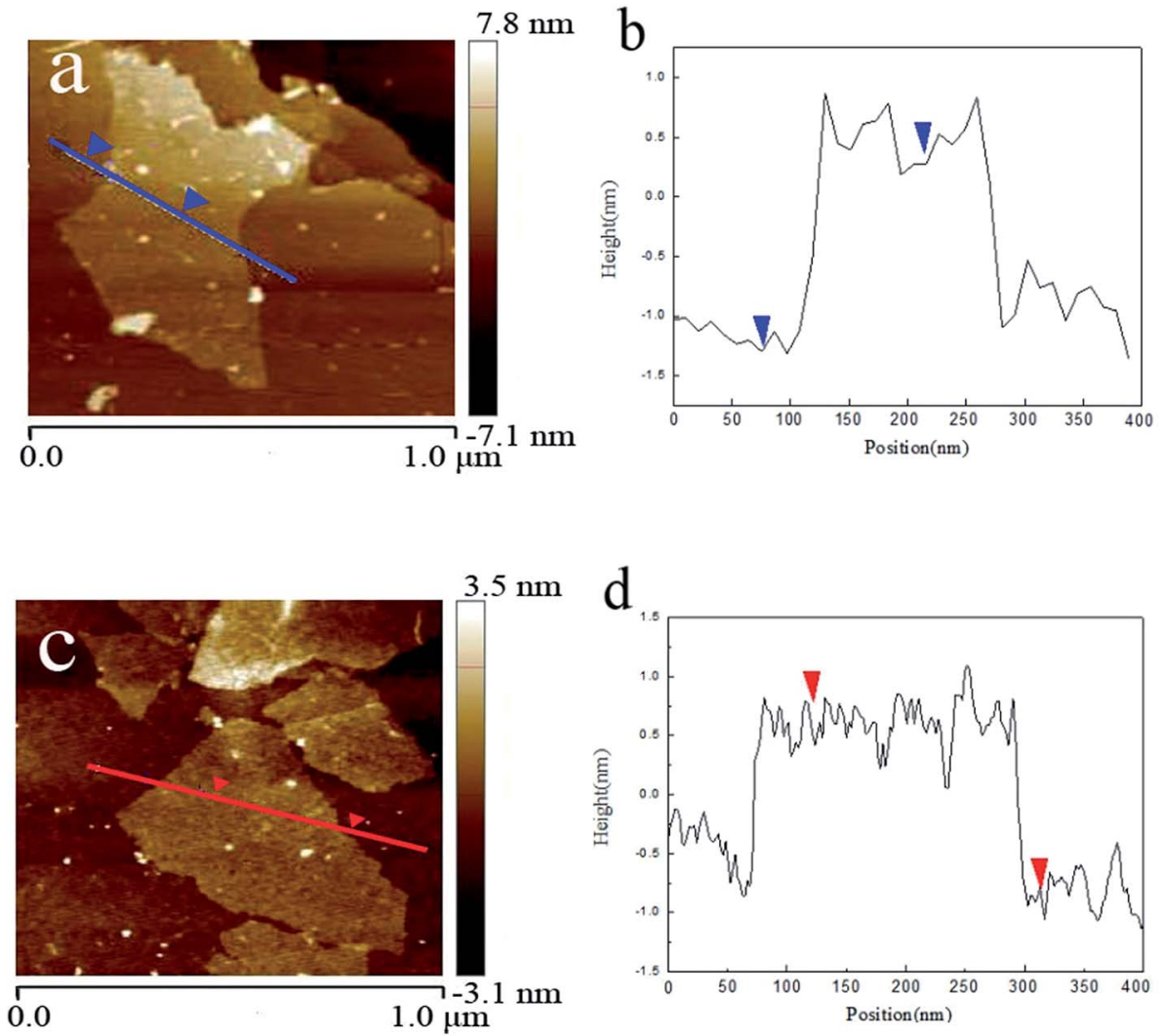

Fig. 4 2D AFM image and height profile of $G O(a, b)$ and $M A H-G O(c, d)$. 
modification didn't change the original nanosheets structure and morphology of GO.

The lateral sizes and thicknesses of GO and MAH-GO nanosheets were observed by AFM. As shown in Fig. 4, most of GO and MAH-GO nanosheets displayed the lateral sizes ranging from 400 to $800 \mathrm{~nm}$, and the average thicknesses of GO and MAH-GO was found to be $1.1 \mathrm{~nm}$ and $1.3 \mathrm{~nm}$, respectively. The observed thickness of GO indicated that GO nanosheets were successfully exfoliated with a single layer, which was consistent with other literature. ${ }^{\mathbf{8}, 37}$ Furthermore, the thickness of MAH-GO was close to that of GO, further confirming that MAH functionalized GO didn't affect the nanosheets structure and morphology of GO.

The Raman spectra of the GO and MAH-GO nanosheets (Fig. 5) show the positions and intensities of $\mathrm{D}$ peak and $\mathrm{G}$ peak. $\mathrm{D}$ broad band at $1350 \mathrm{~cm}^{-1}$ and $\mathrm{G}$ broad band at $1600 \mathrm{~cm}^{-1}$ denote $\mathrm{sp}^{3}$ and $\mathrm{sp}^{2}$ hybridized carbon atoms, corresponding to the disordered and ordered carbon structures of GO

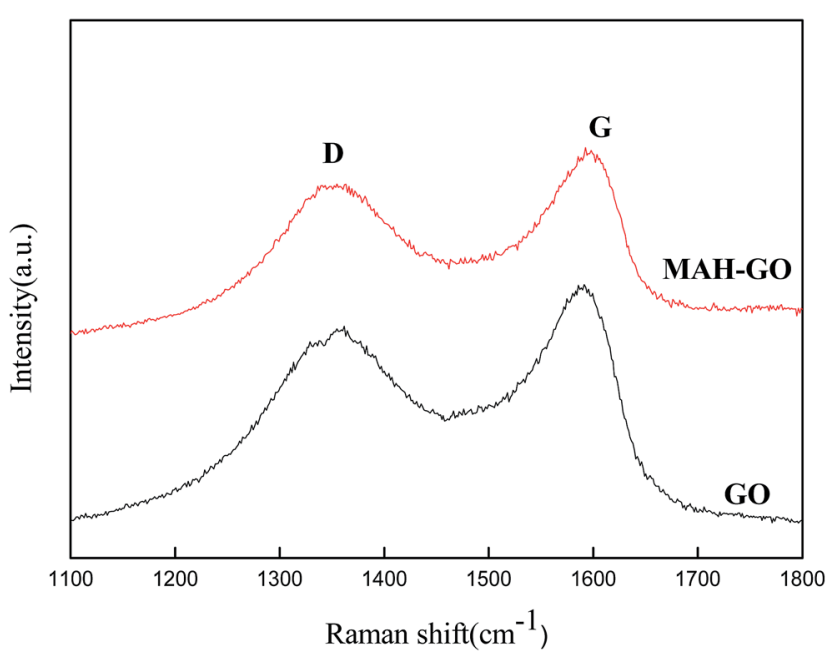

Fig. 5 Raman spectra of $\mathrm{GO}$ and $\mathrm{MAH}-\mathrm{GO}$.

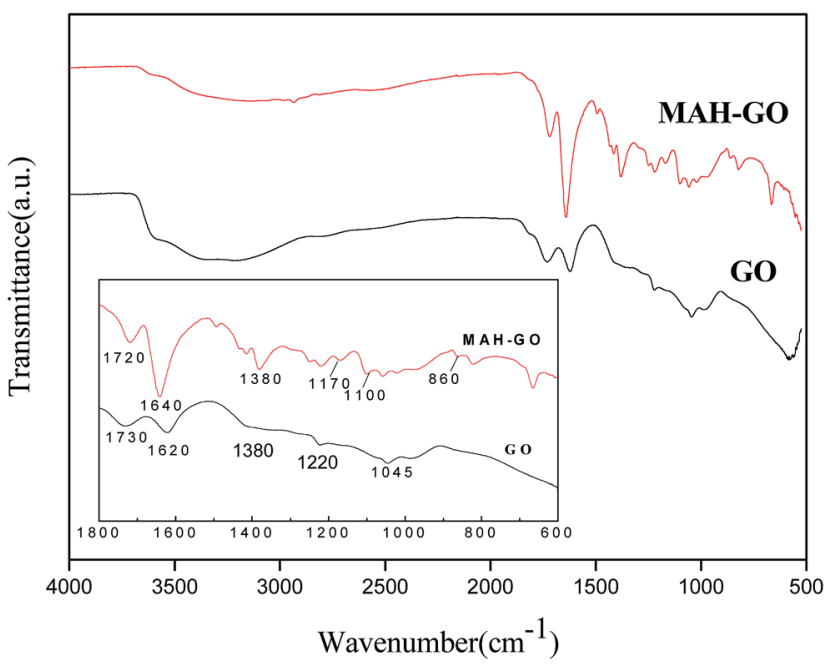

Fig. 6 FTIR spectra of GO and MAH-GO. nanosheets, respectively. The Raman spectrum of MAH-GO was highly similar to that of GO, indicating that MAH-GO still kept the skeleton structure of GO. But the intensity ratio of $\mathrm{D}$ peak to G peak $\left(I_{\mathrm{D}} / I_{\mathrm{G}}\right)$ slightly increased from $0.85(\mathrm{GO})$ to $0.89(\mathrm{MAH}-$ GO). This result implied the introduction of $\mathrm{sp}^{3}$ defects after GO covalent functionalized with MAH.

FTIR was used to investigate the presence of functional groups in GO and MAH-GO nanosheets. As shown in Fig. 6, the GO spectrum displayed several typical characteristic peaks located at 3360, 1730, 1620, 1220 and $1045 \mathrm{~cm}^{-1}$, assigned to the stretching vibrations of $-\mathrm{OH}, \mathrm{C}=\mathrm{O}$, unoxidized $\mathrm{sp}^{2}$ aromatic $\mathrm{C}=\mathrm{C}, \mathrm{C}-\mathrm{O}$ in epoxy groups and $\mathrm{C}-\mathrm{O}$ in alkoxy groups, respectively. This finding confirms that GO nanosheets had abundant oxygen-containing hydrophilic groups, consistent

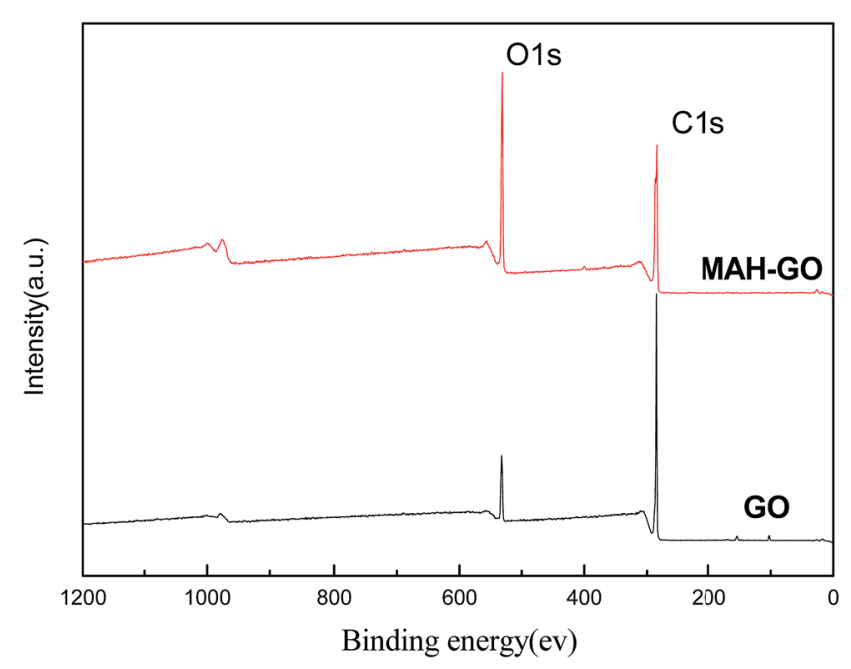

Fig. $7 \mathrm{C}$ 1s and $\mathrm{O}$ 1s XPS spectra of $\mathrm{GO}$ and MAH-GO.
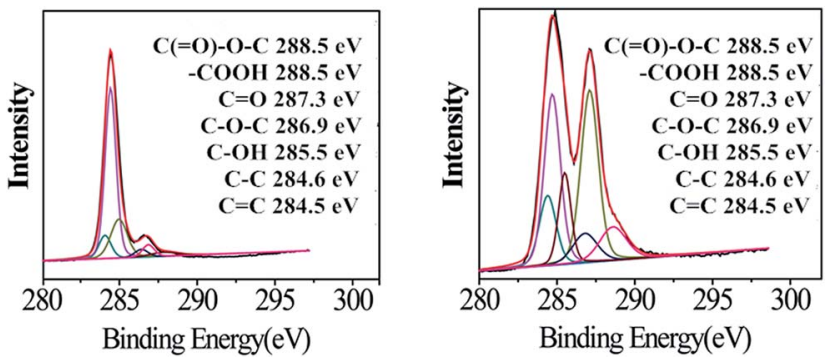

Fig. $8 \mathrm{C}$ 1s XPS spectra of (a) $\mathrm{GO}$ and (b) MAH-GO.

Table 3 Elemental composition and chemical bonding peak area of $\mathrm{GO}$ and $\mathrm{MAH}-\mathrm{GO}$

\begin{tabular}{|c|c|c|c|c|c|}
\hline \multirow[b]{2}{*}{ Sample } & \multicolumn{2}{|c|}{$\begin{array}{l}\text { Atomic } \\
\text { concentration } \\
(\%)\end{array}$} & \multicolumn{3}{|c|}{ Chemical bonding peak area (\%) } \\
\hline & O 1s & C $1 \mathrm{~s}$ & $-\mathrm{C}(=\mathrm{O}) \mathrm{O}$ & $-\mathrm{C}-\mathrm{OH}$ & $-\mathrm{C}=\mathrm{C}-$ \\
\hline GO & 12.88 & 87.12 & 3.50 & 20.39 & 9.19 \\
\hline MAH-GO & 25.95 & 74.05 & 9.35 & 11.66 & 12.33 \\
\hline
\end{tabular}




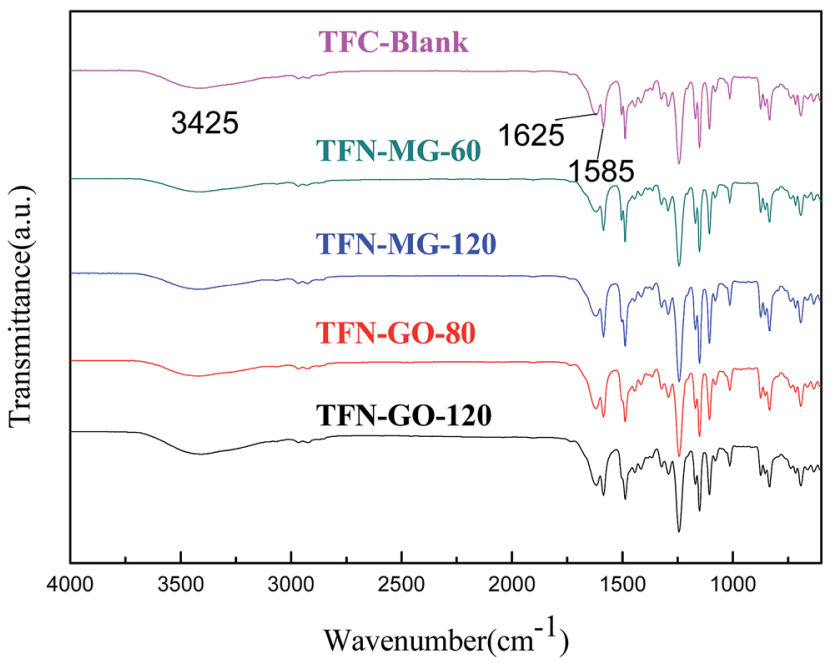

Fig. 9 ATR-FTIR spectra of prepared membranes.
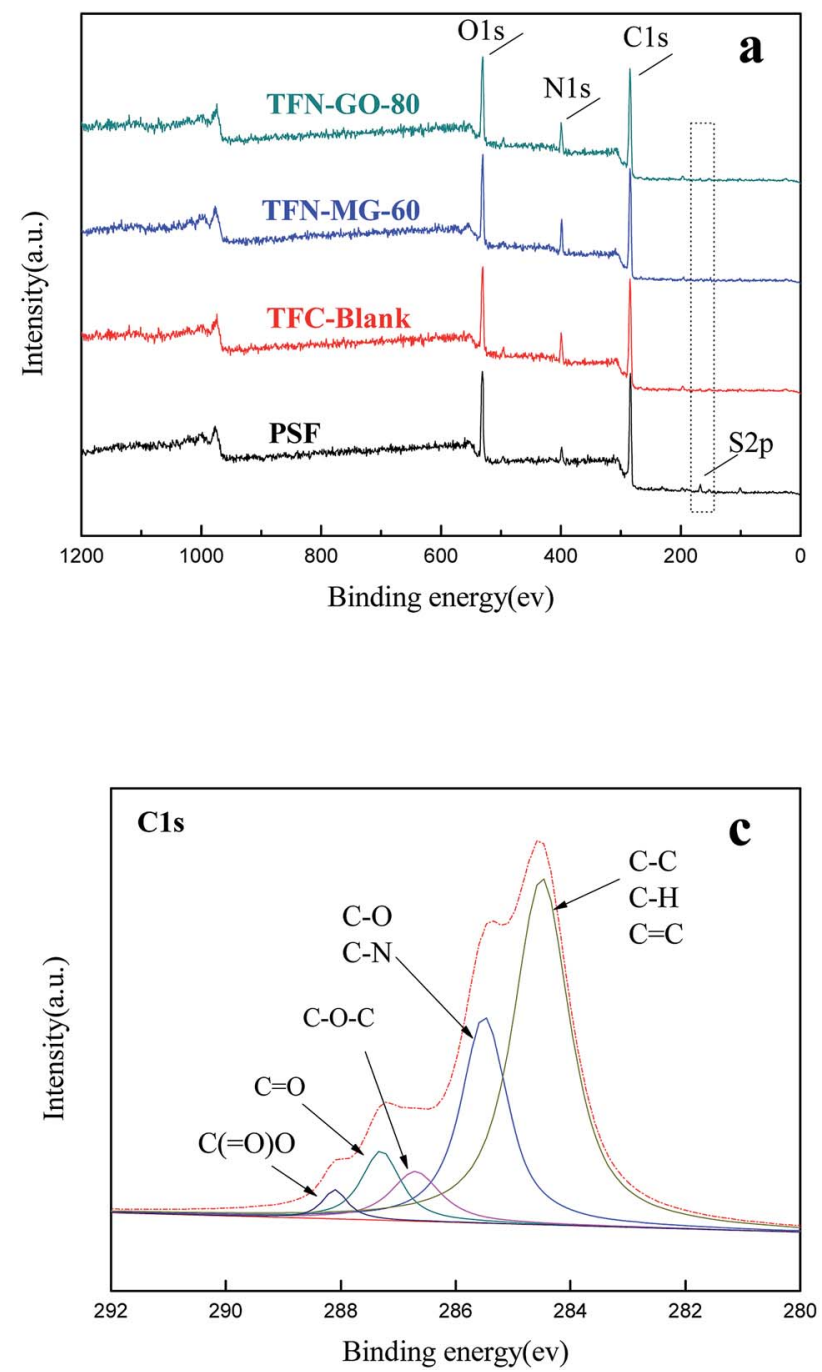

with the previous reports. ${ }^{\mathbf{8} 38}$ After surface covalent modification with $\mathrm{MAH}$, the peaks of $-\mathrm{OH}$ of the carboxyl group $\left(1380 \mathrm{~cm}^{-1}\right)$, $\mathrm{C}=\mathrm{C}\left(1640 \mathrm{~cm}^{-1}\right)$ and $\mathrm{C}=\mathrm{O}\left(1720 \mathrm{~cm}^{-1}\right)$ became stronger, but the broad band of $-\mathrm{OH}\left(3360 \mathrm{~cm}^{-1}\right)$ became weaken. Furthermore, MAH-GO showed a new peak at $860 \mathrm{~cm}^{-1}$ assigned to the in-plane bending vibration of $\mathrm{C}-\mathrm{H}$ of $\mathrm{CH}=\mathrm{CH}$ group. Two additional new peaks at 1100 and $1170 \mathrm{~cm}^{-1}$ were assigned to the stretching vibration of $\mathrm{C}-\mathrm{O}$ of the ester group. All the above observations provided clear evidences that MAH successfully reacted with the electrophilic groups of the GO nanosheets and generated the new GO-MAH nanosheets.

XPS was further adopted to investigate the chemical compositions of GO and MAH-GO nanosheets. As illustrated in Fig. 8, the $\mathrm{C}$ 1s spectra of GO and MAH-GO contain six peaks, corresponded to $\mathrm{C}=\mathrm{C}(284.5 \mathrm{eV}), \mathrm{C}-\mathrm{C}(284.6 \mathrm{eV}), \mathrm{C}-\mathrm{OH}(285.5 \mathrm{eV})$, $\mathrm{C}-\mathrm{O}-\mathrm{C}(286.9 \mathrm{eV}), \mathrm{C}=\mathrm{O}(287.3 \mathrm{eV})$ and $\mathrm{C}(=\mathrm{O}) \mathrm{O}(288.5 \mathrm{eV})$ groups, respectively. According to the Fig. 7 and Table 3, compared with that of GO, the oxygen atomic concentration of MAH-GO was remarkably higher due to the successful
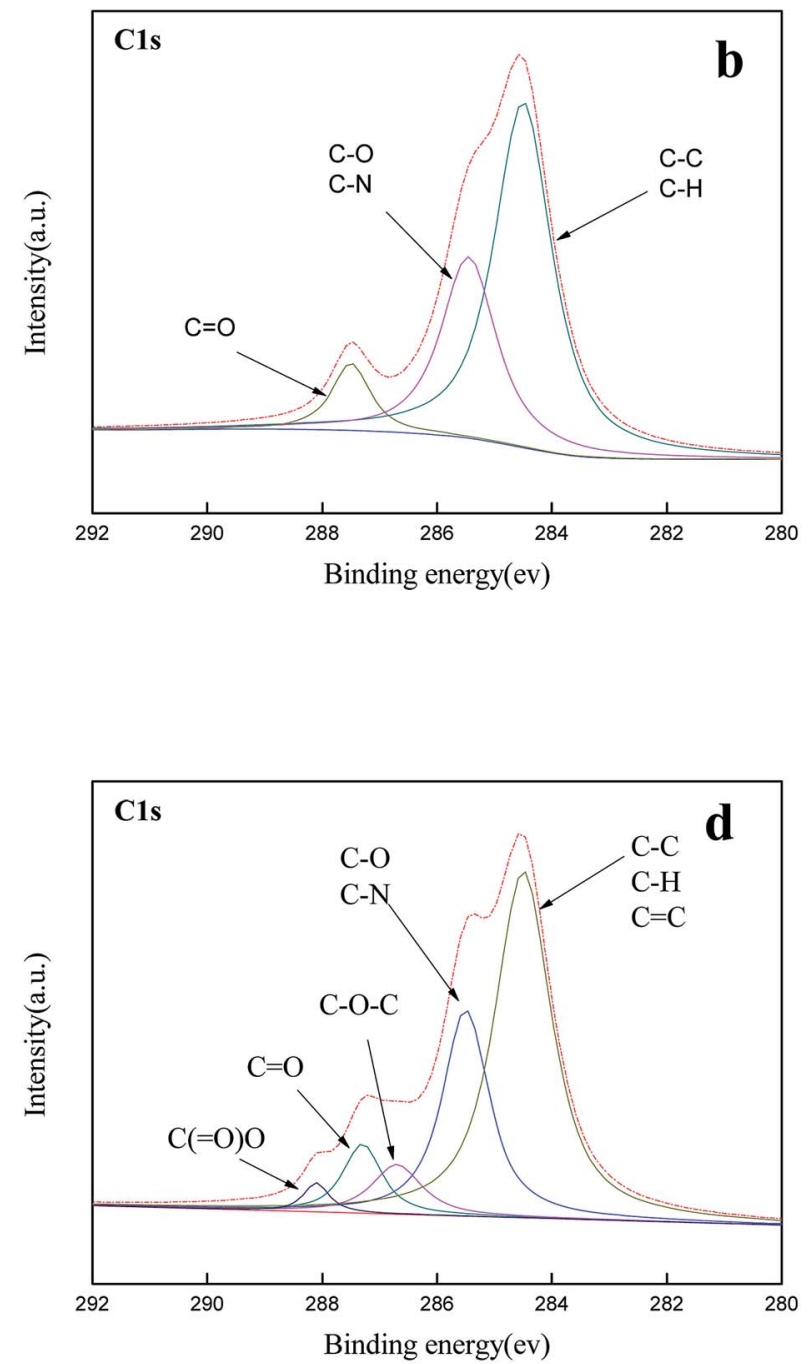

Fig. 10 (a) XPS full-scan spectra of PSf substrate and composite NF membranes; high-resolution C 1s spectra of (b) TFC-blank, (c) TFN-MG-60 and (d) TFN-GO-80. 
introduction of MAH molecules carrying substantial amounts of oxygen atoms. Furthermore, the peak area percentage of $-\mathrm{C}(=\mathrm{O})$ $\mathrm{O}$ and $-\mathrm{C}=\mathrm{C}$ - groups increased from $3.50 \%$ to $9.35 \%$ and $9.19 \%$ to $12.33 \%$, respectively. Meanwhile, the peak area percentage of $-\mathrm{C}-\mathrm{OH}$ groups decreased from $20.39 \%$ to $11.66 \%$, which suggested that the $\mathrm{C}-\mathrm{OH}$ groups acted as electrophilic groups and reacted with the MAH molecules (see Fig. 1). The outstanding change of these functional group concentrations implied successful carboxylation of GO, confirming the characterization results of FTIR analysis.

\subsection{Characterization of composite NF membranes}

The surface chemical structures of composite and support membranes were analyzed by ATR-FTIR as shown in Fig. 9. The composite NF membranes demonstrated characteristic peaks at 1625, 1585 and $3425 \mathrm{~cm}^{-1}$ attributed to the carbonyl stretching vibration of amide-I, the couplings of in-plane $\mathrm{N}-\mathrm{H}$ bending and $\mathrm{C}-\mathrm{N}$ stretching vibrations of amide II band, and the hydroxyl stretching vibration, respectively. ${ }^{27,28}$ These results suggested the successful formation of PPA layer on PSf support membrane surface during the IP process. Nevertheless, TFN membranes embedded with a small amount of nanofillers didn't present detectable variation in comparison with the TFCblank membrane. This may be because the concentration of MAH-GO or GO nanosheets incorporated in PPA layer was overly low for detection by ATR-FTIR.

In order to verify that the selective layers of composite $\mathrm{NF}$ membranes were successfully modified with MAH-GO or GO, XPS analysis was further carried out to investigate the elemental compositions of four kinds of membranes. As shown by the fullscan spectra in Fig. 10(a), all the membranes demonstrated four peaks at binding energy of 167.2, 284.5, 399.2 and $530.8 \mathrm{eV}$, representing the $\mathrm{S} 2 \mathrm{p}, \mathrm{C} 1 \mathrm{~s}, \mathrm{~N}$ 1s and $\mathrm{O}$ 1s regions, which were consistent with the previous report. ${ }^{27}$ The corresponding atomic concentrations were listed in Table 4. Compared with the PSf substrate, the $\mathrm{N}$ atomic concentrations of composite $\mathrm{NF}$ membranes significantly increased, while their $\mathrm{S}$ atomic concentrations decreased. It suggested that an ultrathin PPA active skin layer was successfully formed on the PSf support membrane. Although the concentration of the added nanofiller in TFN-MG-60 was lower than TFN-GO-80, the skin layer of TFNMG-60 still showed the higher oxygen content, probably due to the abundant oxygen element in MAH-GO nanosheets. Fig. 10(b-d) show the high resolution $\mathrm{C}$ 1s spectra. Compared with the TFC-blank membrane, TFN-MG-60 and TFN-GO-80 had the higher percentage of $-\mathrm{C}(=\mathrm{O}) \mathrm{O}$, which suggested that the

Table 4 Elemental composition of different PPA membranes and PSf support membrane analyzed by XPS

\begin{tabular}{llrrr}
\hline Membrane ID & C (\%) & N (\%) & O (\%) & S (\%) \\
\hline TFC-blank & 72.52 & 10.02 & 17.32 & 0.14 \\
TFN-MG-60 & 70.63 & 10.05 & 19.04 & 0.28 \\
TFN-GO-80 & 70.86 & 10.93 & 17.94 & 0.27 \\
PSf support & 74.3 & 4.67 & 19.67 & 1.36
\end{tabular}

PPA active layer had been successfully modified by MAH-GO and GO nanosheets.

The effect of MAH-GO or GO concentrations on the surface hydrophilicities of composite NF membranes was shown in Fig. 11. The PSf substrate had a very high water contact angle (WCA) of $81.4^{\circ}$ due to the inherently hydrophobic characteristic of PSf chemical structure. But WCA of the TFC-blank membrane was significantly reduced to $44.5^{\circ}$, which can be attributed to the presence of the amide bonds and carboxyl groups (generated from the partial hydrolysis of the acyl chloride group) of the top PPA selective layer. ${ }^{39}$ After incorporation of MAH-GO or GO into the PPA selective layers, the WCA of both TFN-MG and TFN-GO series membranes gradually decreased with the increase of MAH-GO and GO concentrations. The WCA of TFNMG-120 and TFN-GO-120 was reduced to $22.3^{\circ}$ and $30.2^{\circ}$, respectively. These results suggested that TFN membranes became more hydrophilic with increasing MAH-GO and GO contents in the active layer, which arose from the oxygencontaining hydrophilic groups in MAH-GO and GO nanosheets. $^{28,39}$ Furthermore, it was noted that TFN-MG series membranes possessed considerably lower WCA than TFN-GO series membranes, because MAH-GO demonstrated stronger hydrophilic property than GO, which was expected to enhance water flux. ${ }^{28}$ It's widely acknowledged that the WCA is mainly

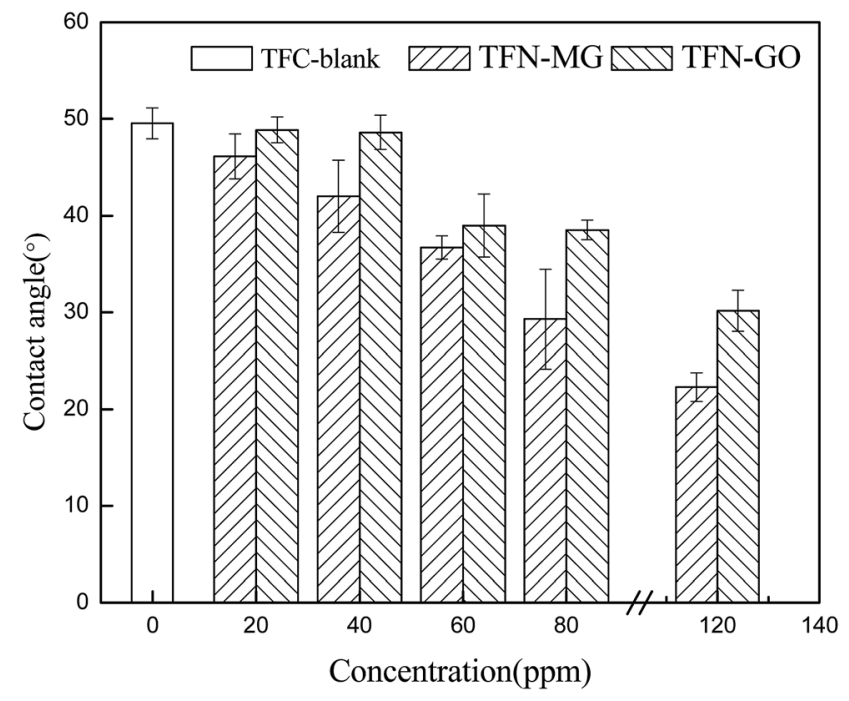

Fig. 11 Contact angles of composite NF membranes as a function of nanofiller concentrations in the aqueous solution.

Table 5 Roughness of prepared membranes

\begin{tabular}{lccc}
\hline & \multicolumn{2}{c}{ Roughness $(\mathrm{nm})$} & \\
\cline { 2 - 4 } Membrane ID & $R_{\mathrm{a}}$ & $R_{\mathrm{q}}$ & $R_{\mathrm{z}}$ \\
\hline TFC-blank & 22.9 & 29.2 & 83.2 \\
TFN-MG-60 & 5.43 & 7.57 & 10.9 \\
TFN-MG-120 & 9.64 & 12.6 & 45.6 \\
TFN-GO-80 & 21.3 & 16.3 & 64.1 \\
TFN-GO-120 & 15.4 & 19.6 & 43.9
\end{tabular}


affected by the intrinsic wettability of membrane material and the membrane surface roughness. Membrane surface with more hydrophilic groups and higher surface roughness leads to a smaller WCA value. As listed in Table 5, the surface roughness varied within $30 \mathrm{~nm}$. Therefore, the WCA affected by surface roughness could be neglected compared with the hydrophilicity enhancement of membrane surface.
According to Fig. 12, both TFC-blank and TFN membranes demonstrated extremely dense and rough top surfaces and the typically composite structure consisting of a thin active skin layer and a finger-like porous transition layer. Moreover, aggregated clusters were observed on the top surfaces when the nanofiller concentration was $120 \mathrm{ppm}$, which mainly resulted from the aggregation of MAH-GO and GO at the high
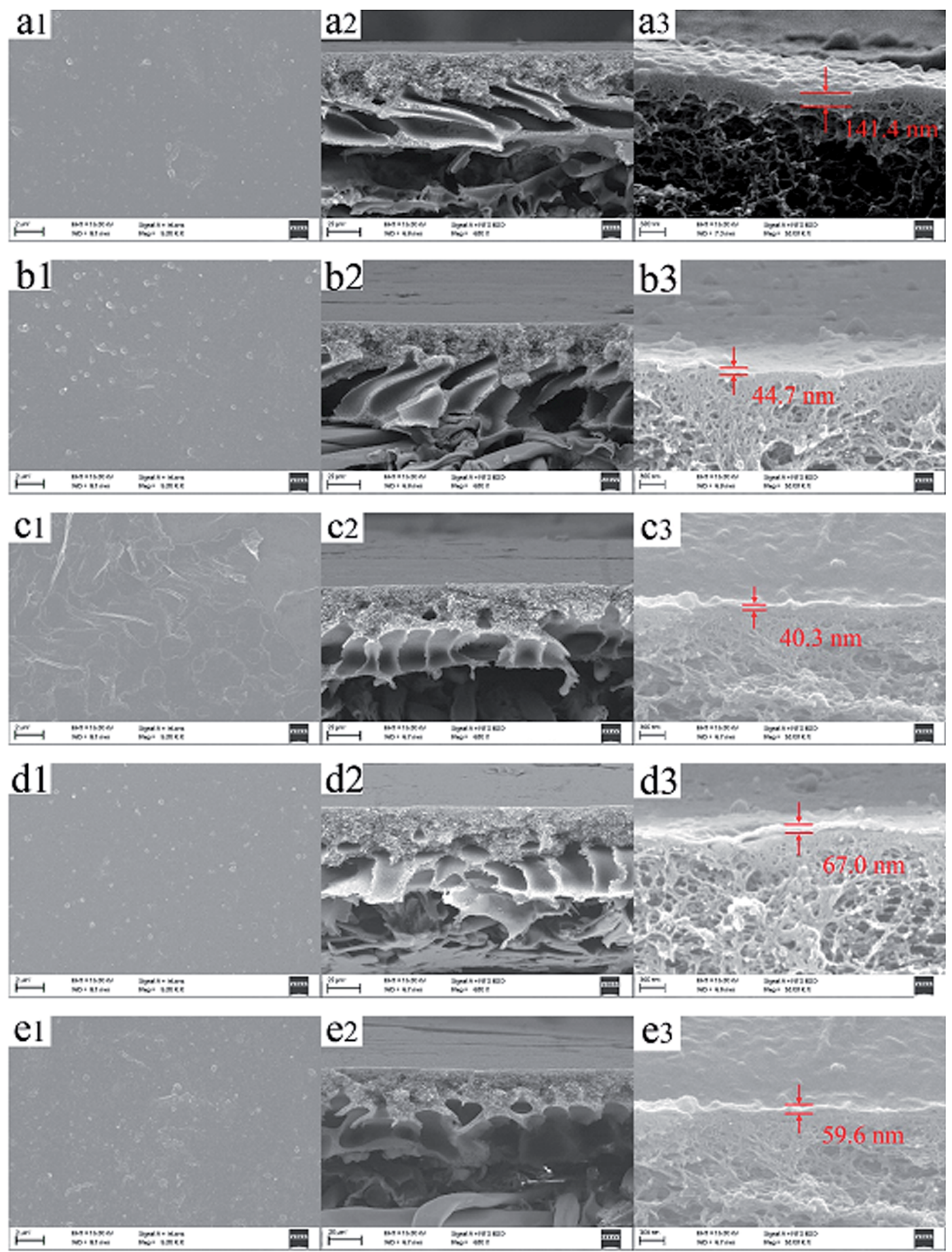

Fig. 12 SEM images of the top surfaces (a1-e1) and cross-sections ((a2-e2) low magnification; (a3-e3) high magnifications). (a) (TFC-blank); (b) (TFN-MG-60); (c) (TFN-MG-120); (d) (TFN-GO-80); (e) (TFN-GO-120). 
concentration. The thickness of PPA skin layer decreased with the increase of MAH-GO and GO concentration. The TFC-blank membrane had a PPA thin-film layer with a thickness of $141.4 \mathrm{~nm}$, but the thickness of TFN-MG-120 and TFN-GO-120 were reduced to 40.3 and $59.6 \mathrm{~nm}$, respectively. The decrease of thickness of PPA top skin layer can increase water permeability due to the decrease of the membrane resistance.

The surface roughness of composite membranes was observed by AFM (Fig. 13). Both TFN-MG and TFN-GO membranes possessed smaller $R_{\mathrm{q}}$ values compared with TFCblank. However, the surface roughness at $120 \mathrm{ppm}$ was higher
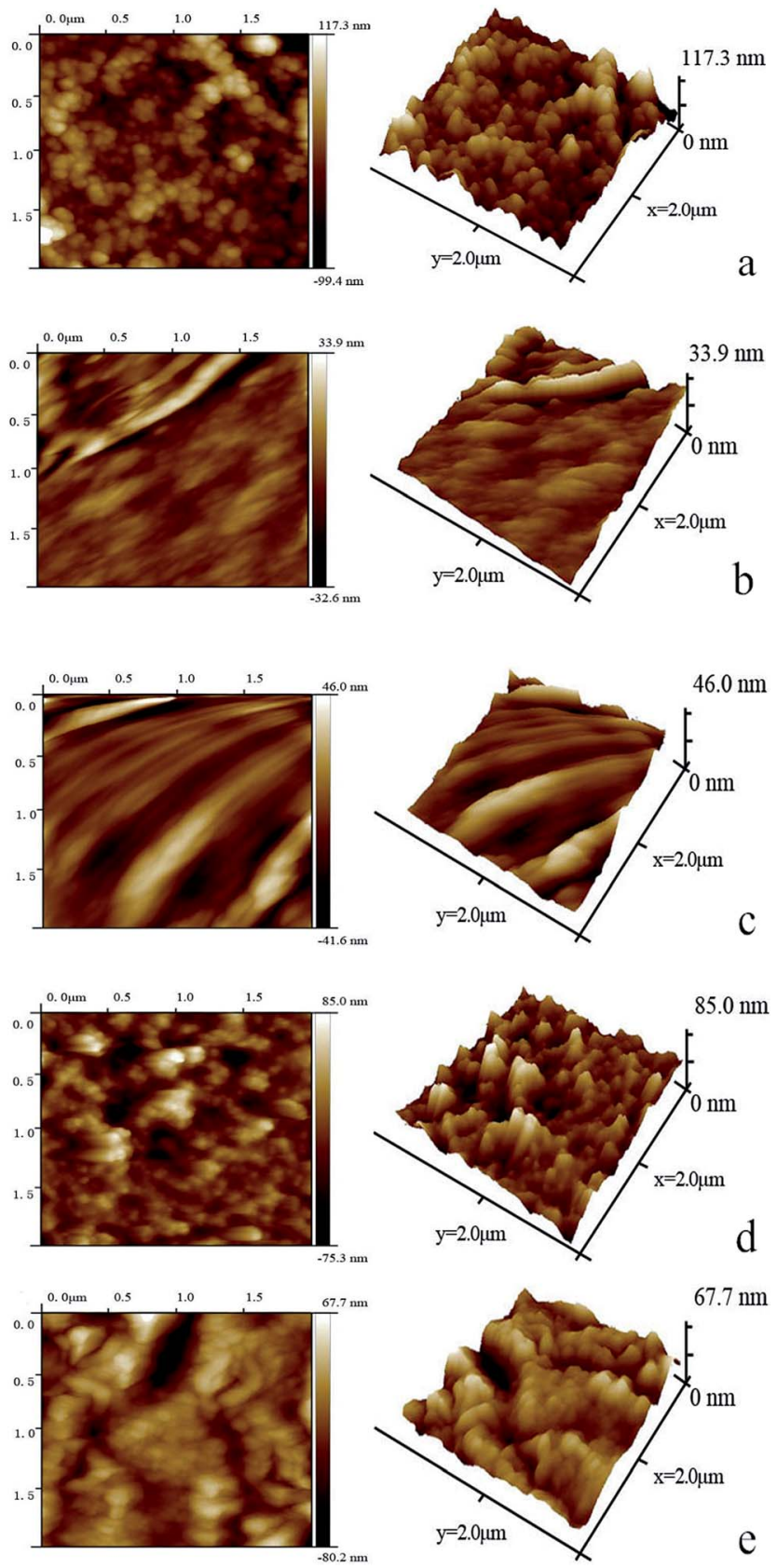

Fig. 13 Two- and three-dimensional AFM surface topography of TFCblank (a), TFN-MG-60 (b), TFN-MG-120 (c), TFN-GO-80 (d), TFN-GO120 (e). than that at $60 \mathrm{ppm}$ regardless of the TFN-MG and TFN-GO membranes, which resulted from the surface-located clusters formed due to the aggregation of MAH-GO and GO at $120 \mathrm{ppm}^{28}$ The decrease of the roughness and the thickness of the PPA skin layer was probably due to the retardation of PIP diffusion into the organic solvent by the MAH-GO and GO nanosheets. ${ }^{24}$ Generally, the membrane surfaces with higher hydrophilicity and lower roughness possess better antifouling property. Consequently, the TFN-MG and TFN-GO membranes were expected to exhibit better antifouling property than the TFC-blank membrane.

\subsection{Performance of composite NF membranes}

The effect of the nanofiller concentration on the membrane performance was evaluated in terms of water permeability

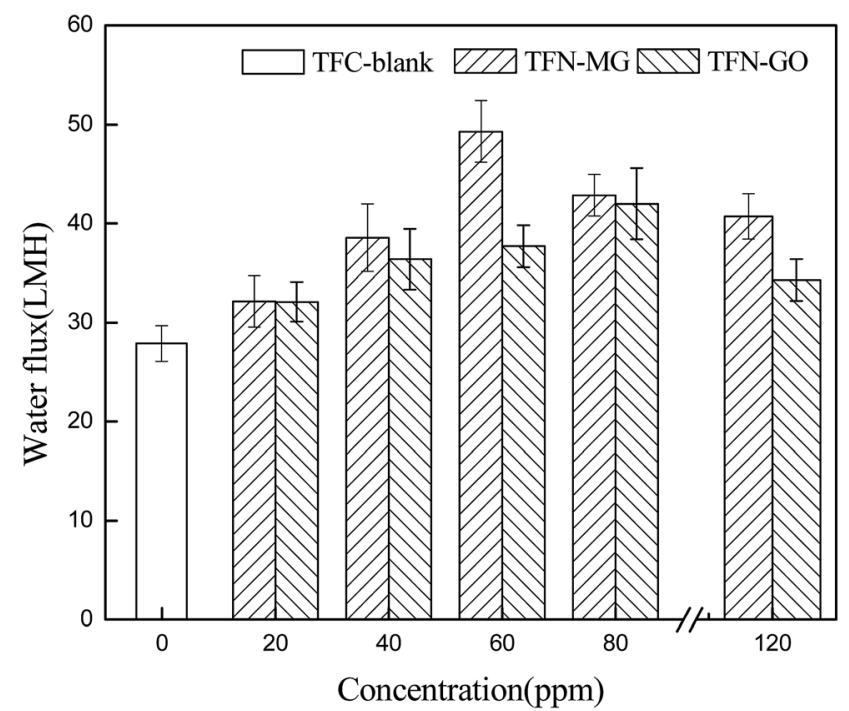

Fig. 14 Effect of nanofiller concentration on water flux of composite NF membranes.

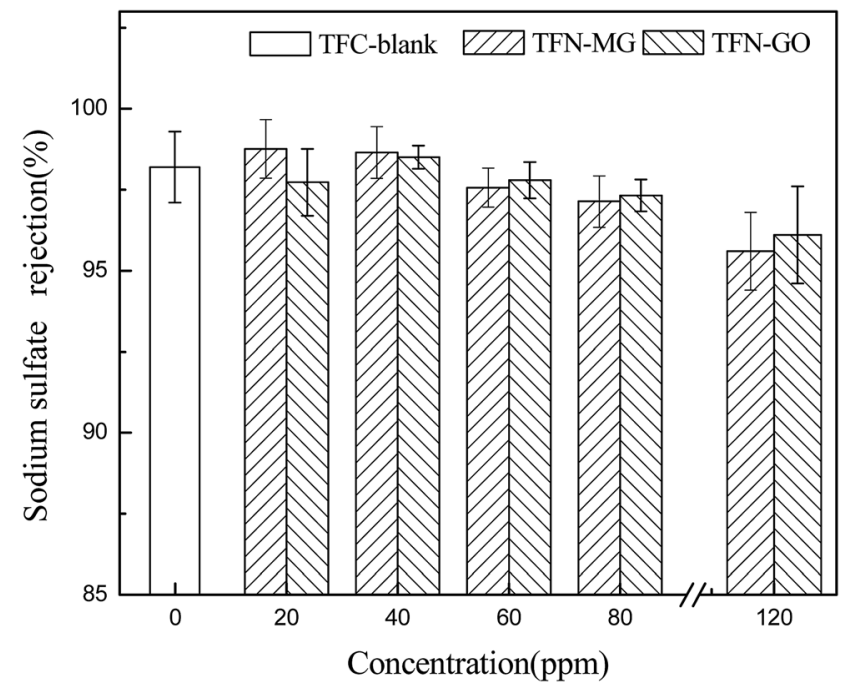

Fig. 15 Effect of nanofiller concentration on sodium sulfate rejection of composite NF membranes. 
(Fig. 14) and salt rejection (Fig. 15). At low nanofiller concentration, the pure water fluxes of both TFN-MG and TFN-GO series membranes increased significantly with the increasing MAH-GO and GO concentrations. TFN-MG-60 and TFN-GO-80 exhibited the largest water flux among TFN-MG and TFN-GO series membranes, respectively. The water fluxes of TFN-MG-60 and TFN-GO-80 reached $49.3 \mathrm{~L} \mathrm{~m}^{-2} \mathrm{~h}^{-1}$ and $42.0 \mathrm{~L} \mathrm{~m}^{-2} \mathrm{~h}^{-1}$, respectively, which corresponded to $176.7 \%$ and $150.5 \%$ of TFCblank. Meanwhile, there was no obvious loss of $\mathrm{Na}_{2} \mathrm{SO}_{4}$ rejection at low nanofiller concentrations, which suggested that the increment of water flux wasn't caused by the membrane defect due to the addition of MAH-GO and GO nanosheets. The enhanced water flux could be a result from the following factors: (1) the stronger membrane hydrophilicity and the smoother membrane surface promoted an overall faster flow of water molecules on the hydrophilic membrane surfaces with less friction, ${ }^{35}$ (2) a relatively loose and thin PPA skin layer was formed because the introduction of MAH-GO or GO nanosheets hindered the diffusion of PIP molecules into the organic phase during the IP process, which reduced the membrane resistance and led to an increased water flux, (3) the introduction of MAH-GO/GO nanosheets probably affected the PPA connections and increased the free volume, and some gaps also inevitably appeared in the interfacial layer between PPA and MAH-GO/GO nanosheets, both the free volume and gaps acted as the molecular channel of water, and (4) more additional water channels were provided by $\mathrm{MAH}$ GO or GO nanosheets, which facilitated water passage through the top skin layer. ${ }^{28}$

When the nanofiller concentration varied from 20 to $80 \mathrm{ppm}$, the salt rejection remained relatively constant regardless of the nanofiller types and concentrations. However, there was an obvious decrease in the salt rejection when the concentration reached $120 \mathrm{ppm}$. This is because when excessive MAH-GO or GO was added into the aqueous phase, some voids were unavoidably introduced in the skin layer due to the limited compatibility between the nanofiller and the polymer matrix. ${ }^{18}$ Furthermore, excessive amount of MAH-GO or GO would

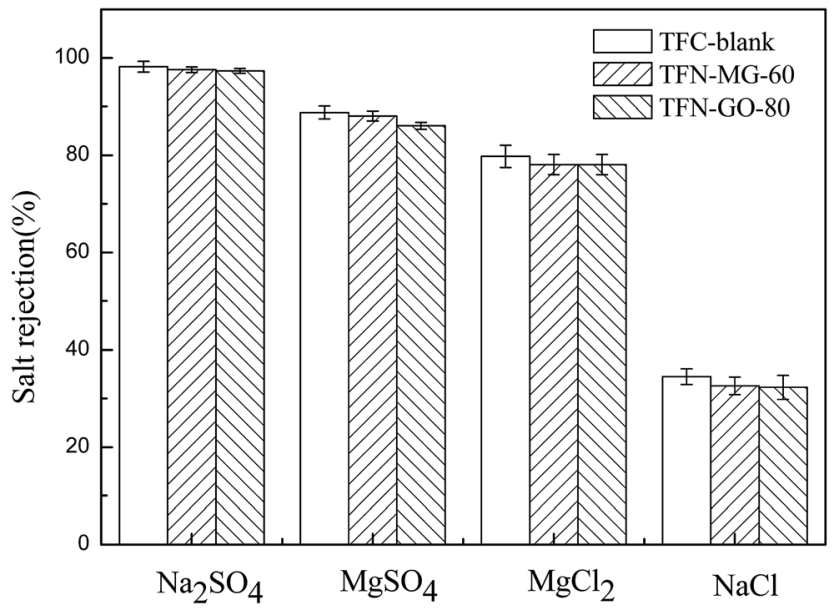

Fig. 16 Salt rejections of composite membranes with different nanofiller concentration. aggregate and affect the formation of PPA skin layer by interfacial reaction between PIP and TMC., ${ }^{\mathbf{9} 28,40}$ Therefore, the combined effects resulted in the reduction of salt rejection.

Four different salt solutions (2000 ppm of $\mathrm{Na}_{2} \mathrm{SO}_{4}, \mathrm{MgSO}_{4}$, $\mathrm{MgCl}_{2}$ and $\mathrm{NaCl}$ ) were further used to evaluate the salt rejection characteristics of the TFC-blank and optimal TFN membranes (Fig. 16). It is well established that the salt rejection of NF membrane is closely associated with the size exclusion effect and Donnan exclusion effect. In this study, the three tested composite NF membranes all showed the same sequence of salt rejections: $\mathrm{Na}_{2} \mathrm{SO}_{4}>\mathrm{MgSO}_{4}>\mathrm{MgCl}_{2}>\mathrm{NaCl}$, which was consistent with the negatively charged NF membrane characteristics. As illustrated in Fig. 17, these three NF membranes were negatively charged once the $\mathrm{pH}$ value was greater than the isoelectric point (IEP), and thus offered a stronger repulsive force to divalent $\mathrm{SO}_{4}{ }^{2-}$ than to monovalent $\mathrm{Cl}^{-}$. Meanwhile, $\mathrm{SO}_{4}{ }^{2-}$ has a lower diffusion coefficient than $\mathrm{Cl}^{-}$due to its larger Stokes radius (Table 2). As a result, $\mathrm{SO}_{4}{ }^{2-}$ needed to overcome more resistance to penetrate the membrane, which led to higher rejection to $\mathrm{SO}_{4}{ }^{2-}$ than to $\mathrm{Cl}^{-}$. On the other hand, based on the Donnan electrostatic exclusion mechanism, the rejection towards the salts having the same anion mainly depends on the diffusion coefficient of cations. Therefore, the higher diffusivity of $\mathrm{Na}^{+}$than that of $\mathrm{Mg}^{2+}$ resulted in the lower rejection to $\mathrm{NaCl}$ than to $\mathrm{MgCl}_{2}$.

It is also interesting to note that two opposite effects were present here for the salt rejection. As described above that the top selective layer of TFN membrane became loose after introducing MAH-GO and GO nanosheets, which decreased the salt rejection. However, TFN-MG-60 and TFN-GO-80 membranes possessed more negative charge attributed to the ionisable groups in MAH-GO and GO, greatly increasing the salt rejection due to the strong Donnan effect. Consequently, TFN-MG-60 and TFN-GO-80 membranes retained the high salt rejections comparable to that of TFC-blank. Between the two modified TFN membranes, TFN-MG-60 exhibited more negatively charged than TFN-GO-80 due to more $-\mathrm{COOH}$ in MAH-GO,

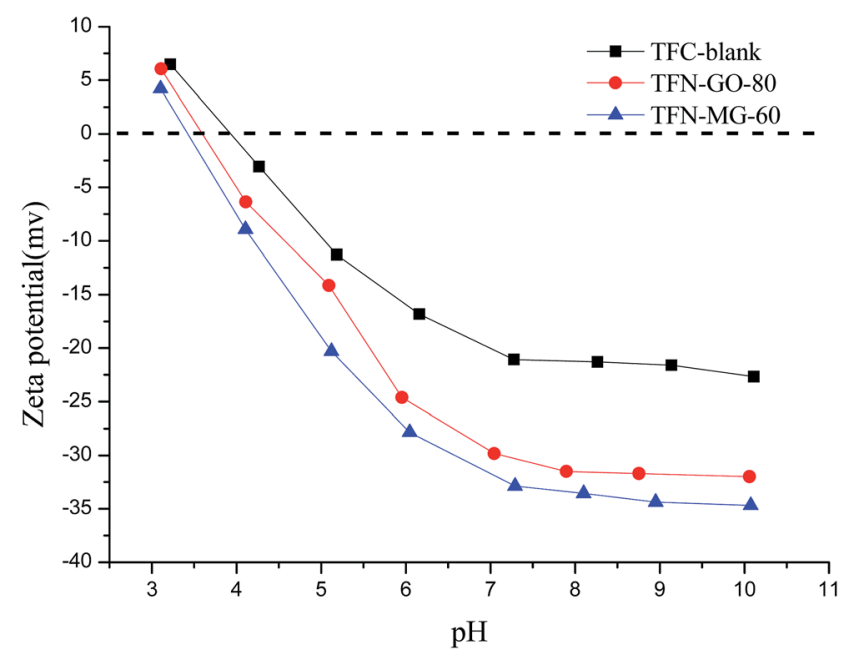

Fig. 17 Membrane zeta potential as a function of $\mathrm{pH}$ in $1 \mathrm{mM} \mathrm{KCl}$ solution. 
which agreed well with the zeta potentials of their nanosheets (Table 6).

A two-cycle cross-flow filtration process was carried out using BSA as a model foulant to evaluate the antifouling properties of the TFC-blank and optimized TFN NF membranes at $0.6 \mathrm{MPa}$ and $25{ }^{\circ} \mathrm{C}$. As illustrated in Fig. 18, the BSA fluxes of all three NF membranes gradually declined as a result of the concentration polarization and membrane fouling. The pure water fluxes couldn't be completely recovered to the initial value after cleaning by fresh water, indicating the irreversible adsorption of some protein molecules on membrane surfaces or nanopores. ${ }^{\mathbf{4 1}}$ Interestingly, both of the engineered TFN membranes showed higher normalized fluxes than TFC-blank membrane, which suggested that the antifouling property was significantly improved by incorporation of MAH-GO and GO nanosheets. Furthermore, the normalized flux of TFN-MG-60 was higher than that of TFN-GO-80. This indicated that TFN-MG-60 possessed the superior antifouling performance than TFN-GO80. On one hand, the hydrophilic groups of MAH-GO and GO in PPA matrix may facilitate to form a regular hydration layer on the membrane surface via hydrogen bond, and the protein was excluded from the hydration layer to avoid the substantial entropy loss caused by the entrance of large protein molecules into the membrane surface. ${ }^{20}$ On the other hand, given that the model foulant (BSA) was negatively charged in this experiment, the BSA adsorption on the membrane surface with a more negatively charge was alleviated due to the charge repulsion effect. Therefore, the sequence of antifouling performance was TFN-MG-60 > TFN-GO-80 > TFC-blank. This result matched very well with their sequences of hydrophilicity and surface charge.

Compared with PPA NF membranes using GO in the aqueous phase $^{42}$ or GO-COCl in the organic phase, ${ }^{37}$ the nanocomposite NF membrane using MAH-GO in this study exhibited the better performance.

After a long exposure period ( $72 \mathrm{~h}$ ) to a $2000 \mathrm{ppm}$ chlorine solution, the chlorine resistances of the TFC-blank and optimal TFN membranes were evaluated based on the normalized water flux and salt rejection. As shown in Fig. 19, the three NF membranes exhibited an obvious increase in water flux and a slight decrease in salt rejection after chlorine treatment. It was noted that both TFN-MG-60 and TFN-GO-80 membrane showed higher stability under chlorine attack, compared with TFCblank. This demonstrates that the chlorine resistance was effectively enhanced by incorporation of a small amount of MAH-GO and GO nanosheets in the PPA active layer. Chlorine is able to degrade polyamide macromolecules via a nucleophilic substitution reaction between chlorine and the hydrogen of the secondary amide group $(-\mathrm{NH})$ in polyamide, ${ }^{\mathbf{4 3}}$ and thus reduce the membrane performance. Notably, the secondary amines of

Table 6 Zeta potentials of MAH-GO and GO nanosheets

\begin{tabular}{lll}
\hline Nanofiller & $\begin{array}{l}\text { Concentration } \\
(\mathrm{ppm})\end{array}$ & Zeta potentials $(\mathrm{mV})$ \\
\hline MAH-GO & 60 & $-40.0 \pm 1.4$ \\
GO & 80 & $-27.9 \pm 0.2$
\end{tabular}

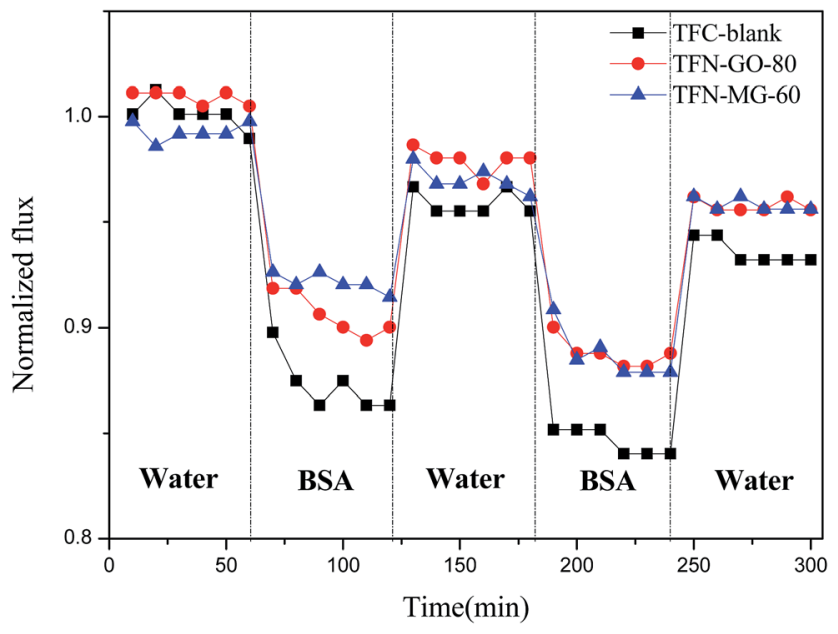

Fig. 18 Time-dependent normalized flux of NF membranes.
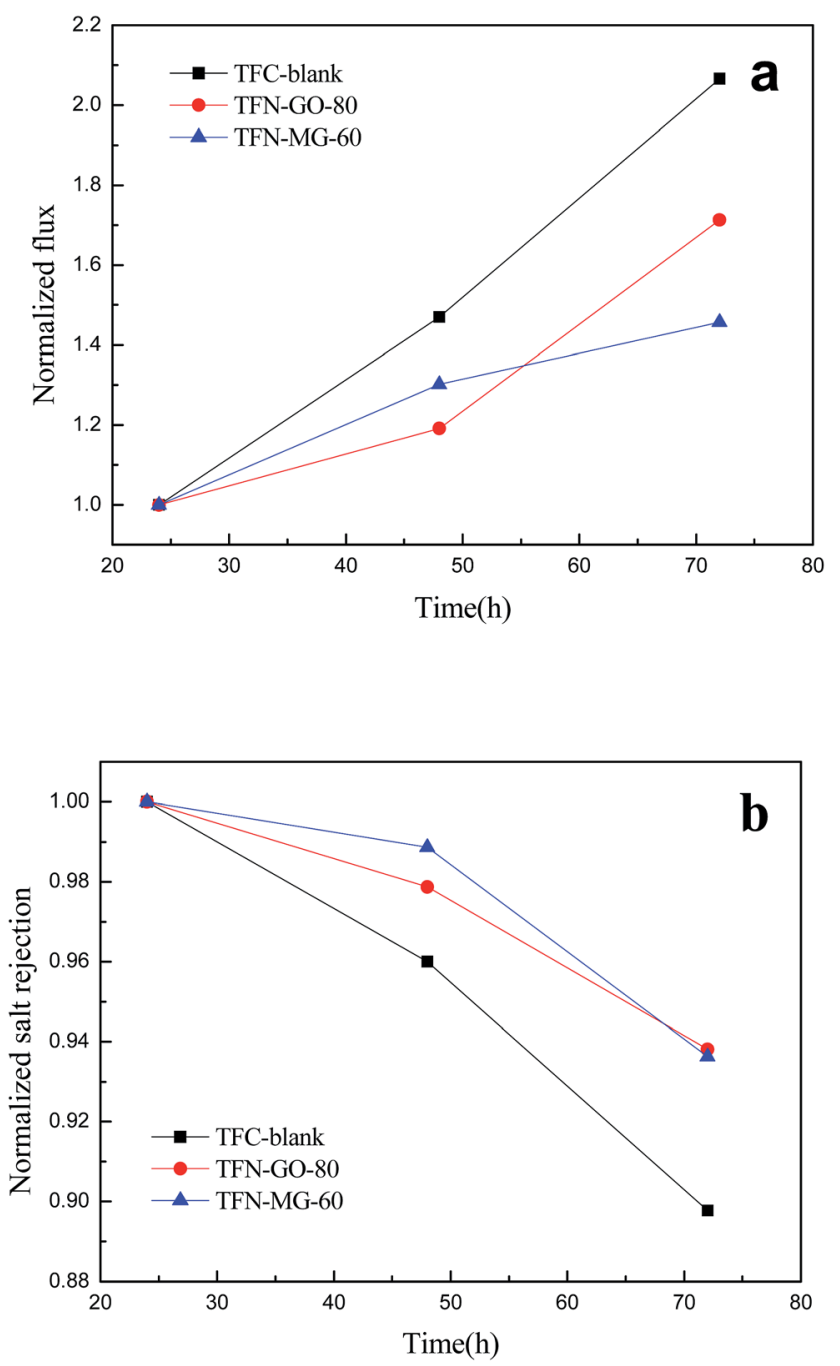

Fig. 19 Effects of chlorine exposure time on water flux (a) and salt rejection (b) of the TFC-blank and optimal TFN membranes. Chlorine treatment was conducted with a $2000 \mathrm{ppm} \mathrm{NaOCl}$ solution ( $\mathrm{pH}$ 7) for $72 \mathrm{~h}$. 
PIP reacted with TMC will change into tertiary amines, which can tolerate the active chlorine attack. However, the other unreacted secondary amines would degrade after the active chlorine attack. The increased chlorine resistance of TFN-MG60 and TFN-GO-80 can be mainly attributed to the hydrogen bonding between PPA and MAH-GO/GO that functioned as a protection mechanism against the chlorine attack. ${ }^{\mathbf{4 4}}$ Moreover, the MAH-GO and GO nanosheets offered additional protection for the underlying PPA against the chlorine attack. ${ }^{45}$

\section{Conclusions}

With the aim of improving membrane performance, this study synthesized MAH-GO by combining MAH molecules with the GO nanosheets and introducing the resulting materials into the PPA skin layer via interfacial polymerization. The XPS analysis verified the successful incorporation of MAH-GO nanosheets in the PPA active layer of modified NF membrane. The effects of the concentrations of MAH-GO and GO nanosheets on the morphologies and performance of the resultant TFN NF membranes were systematically studied. The optimum concentrations of TFN-MG and TFN-GO series membranes were identified to be 60 and $80 \mathrm{ppm}$. Compared with the TFC-blank membrane, both TFN-MG-60 and TFN-GO-80 membranes demonstrated significantly enhanced performance without the reduction of salt rejection. Particularly, the pure water fluxes of TFN-MG-60 and TFN-GO-80 membranes were 76.7\% and 50.5\% higher than that of TFC-blank membrane. Between the two engineered membranes, TFN-MG-60 exhibited superior hydrophilicity, water permeability, antifouling capability and chlorine resistance over TFN-GO-80, largely due to enhanced hydrophilicity and charge density of MAH-GO nanosheets as a result of the increase in the number of carboxyl groups. Therefore, $\mathrm{MAH}$ GO is considered as a promising nanomaterial for developing the high-performance TFN NF membrane to overcome the trade-off effect of conventional TFC membranes.

\section{Conflicts of interest}

There are no conflicts to declare.

\section{Acknowledgements}

We thank the financial supports from the Scientific Research Foundation of Third Institute of Oceanography, SOA (No. 2016036), the Science \& Technology Planning Project of Xiamen City, China (No. 3502Z20172008), the National Natural Science Foundation of China (NSFC 21535007), the Fundamental Research Funds for the Central Universities (No. 20720170027) and the National Natural Science Foundation of China (No. 21736009).

\section{References}

1 W. J. Lau, A. F. Ismail, N. Misdan and M. A. Kassim, Desalination, 2012, 287, 190-199.
2 A. W. Mohammad, Y. H. Teow, W. L. Ang, Y. T. Chung, D. L. Oatley-Radcliffe and N. Hilal, Desalination, 2015, 356, 226-254.

3 Y. Y. Pan, R. P. Xu, Z. H. Lu, S. C. Yu, M. H. Liu and C. J. Gao, J. Membr. Sci., 2017, 523, 282-290.

4 Y. L. Ji, Q. F. An, Y. S. Guo, W. S. Hung, K. R. Lee and C. J. Gao, J. Mater. Chem. A, 2016, 4, 4224-4231.

5 N. Misdan, A. F. Ismail and N. Hilal, Desalination, 2016, 380, 105-111.

6 Y. J. Tang, Z. L. Xu, S. M. Xue, Y. M. Wei and H. Yang, J. Membr. Sci., 2016, 498, 374-384.

7 X. Q. Cheng, Y. Y. Liu, Z. H. Guo and L. Shao, J. Membr. Sci., 2015, 493, 156-166.

8 G. S. Lai, W. J. Lau, P. S. Goh, A. F. Ismail, N. Yusof and Y. H. Tan, Desalination, 2016, 387, 14-24.

9 M. E. A. Ali, L. Y. Wang, X. Y. Wang and X. S. Feng, Desalination, 2016, 386, 67-76.

10 W. J. Lau, S. Gray, T. Matsuura, D. Emadzadeh, J. P. Chen and A. F. Ismail, Water Res., 2015, 80, 306-324.

11 A. F. Ismail, M. Padaki, N. Hilal, T. Matsuura and W. J. Lau, Desalination, 2015, 356, 140-148.

12 Q. Li, Y. H. Wang, J. Song, Y. P. Guan, H. Yu, X. H. Pan, F. Y. Wu and M. Zhang, Appl. Surf. Sci., 2015, 324, 757-764.

13 L. M. Jin, S. L. Yu, W. X. Shi, X. S. Yi, N. Sun, Y. L. Ge and C. Ma, Polymer, 2012, 53, 5295-5303.

14 L. M. Jin, W. X. Shi, S. L. Yu, X. S. Yi, N. Sun, C. Ma and Y. S. Liu, Desalination, 2012, 298, 34-41.

15 H. S. Lee, S. J. Im, J. H. Kim, H. J. Kim, J. P. Kim and B. R. Min, Desalination, 2008, 219, 48-56.

16 B. Rajaeian, A. Rahimpour, M. O. Tade and S. M. Liu, Desalination, 2013, 313, 176-188.

17 S. M. Xue, Z. L. Xu, Y. J. Tang and C. H. Ji, ACS Appl. Mater. Interfaces, 2016, 8, 19135-19144.

18 N. Zarrabi, M. E. Yekavalangi, V. Vatanpour, A. Shockravi and M. Safarpour, Desalination, 2016, 394, 83-90.

19 V. Vatanpour, S. S. Madaeni, R. Moradian, S. Zinadini and B. Astinchap, J. Membr. Sci., 2011, 375, 284-294.

20 L. Yu, Y. T. Zhang, B. Zhang, J. D. Liu, H. Q. Zhang and C. H. Song, J. Membr. Sci., 2013, 447, 452-462.

21 Q. Q. Zhao, J. W. Hou, J. N. Shen, J. D. Liu and Y. T. Zhang, J. Mater. Chem. A, 2015, 3, 18696-18705.

22 J. Zhu, M. Tian, J. Hou, J. Wang, J. Lin, Y. Zhang, J. Liu and B. Van der Bruggen, J. Mater. Chem. A, 2016, 4, 1980-1990.

23 J. I. Paredes, S. Villar-Rodil, A. Martinez-Alonso and J. M. Tascon, Langmuir, 2008, 24, 10560-10564.

24 H. R. Chae, J. Lee, C. H. Lee, I. C. Kim and P. K. Park, J. Membr. Sci., 2015, 483, 128-135.

25 L. He, L. F. Dumee, C. F. Feng, L. Velleman, R. Reis, F. H. She, W. M. Gao and L. X. Kong, Desalination, 2015, 365, 126-135.

26 J. Yin, G. C. Zhu and B. L. Deng, Desalination, 2016, 379, 93101.

27 J. Wang, C. W. Zhao, T. Wang, Z. Wu, X. Li and J. S. Li, RSC $A d v .$, 2016, 6, 82174-82185.

28 S. Bano, A. Mahmood, S. J. Kim and K. H. Lee, J. Mater. Chem. A, 2015, 3, 2065-2071. 
29 S. J. Xia, L. J. Yao, Y. Zhao, N. N. Li and Y. Zheng, Chem. Eng. J., 2015, 280, 720-727.

30 L. Shao, X. Q. Cheng, Z. X. Wang, J. Ma and Z. H. Guo, J. Membr. Sci., 2014, 452, 82-89.

31 R. Ding, H. Q. Zhang, Y. F. Li, J. T. Wang, B. B. Shi, H. Mao, J. C. Dang and J. D. Liu, Chem. Eng. Sci., 2015, 138, 227-238.

32 F. Kim, L. J. Cote and J. Huang, Adv. Mater., 2010, 22, 19541958.

33 L. J. Cote, J. Kim, V. C. Tung, J. Y. Luo, F. Kim and J. X. Huang, Pure Appl. Chem., 2011, 83, 95-110.

34 W. S. Hung, Q. F. An, M. De Guzman, H. Y. Lin, S. H. Huang, W. R. Liu, C. C. Hu, K. R. Lee and J. Y. Lai, Carbon, 2014, 68, 670-677.

35 Q. Xie, S. Zhang, Z. Xiao, X. Hu, Z. Hong, R. Yi, W. Shao and Q. Wang, RSC Adv., 2017, 7, 18755-18764.

36 D. X. Wang, M. Su, Z. Y. Yu, X. L. Wang, M. Ando and T. Shintani, Desalination, 2005, 175, 219-225.
37 P. Wen, Y. B. Chen, X. Y. Hu, B. W. Cheng, D. Q. Liu, Y. F. Zhang and S. Nair, J. Membr. Sci., 2017, 535, 208-220.

38 H. B. Li, H. X. Zhang, X. H. Qin and W. Y. Shi, Appl. Surf. Sci., 2017, 407, 260-275.

39 J. Wang, C. Zhao, T. Wang, Z. Wu, X. Li and J. Li, RSC Adv., 2016, 6, 82174-82185.

40 H. R. Chae, C. H. Lee, P. K. Park, I. C. Kim and J. H. Kim, J. Membr. Sci., 2017, 525, 99-106.

41 L.-L. Hwang, J.-C. Chen and M.-Y. Wey, Desalination, 2013, 313, 166-175.

42 M. Safarpour, V. Vatanpour, A. Khataee and M. Esmaeili, Sep. Purif. Technol., 2015, 154, 96-107.

43 J. Glater, S. K. Hong and M. Elimelech, Desalination, 1994, 95, 325-345.

44 F. Perreault, M. E. Tousley and M. Elimelech, Environ. Sci. Technol. Lett., 2014, 1, 71-76.

45 W. Choi, J. Choi, J. Bang and J. H. Lee, ACS Appl. Mater. Interfaces, 2013, 5, 12510-12519. 